\section{Limites do cuidado: representações e processos inconscientes sobre a população na porta de entrada de um hospital de emergência}

\author{
Health care limits: representations and unconscious \\ processes related to the population at the hospital \\ emergency entrance
}

\author{
${ }^{1}$ Escola Nacional de Saúde \\ Pública Sergio Arouca, \\ Fundação Oswaldo Cruz \\ Rio de Janeiro, Brasil. \\ 2 Programa de Pós- \\ Graduação em Psicologia \\ Universidade Federal \\ Fluminense, Niterói, Brasil. \\ 3 Instituto de Psicologia \\ Universidade de São Paulo, \\ São Paulo, Brasil. \\ Correspondência \\ M. C. Sá \\ Departamento de \\ Administração e \\ Planejamento em Saúde, \\ Escola Nacional de Saúde \\ Pública Sergio Arouca, \\ Fundação Oswaldo Cruz. \\ Rua Leopoldo Bulhões 1480 \\ Rio de Janeiro, $R J$ \\ 21041-900, Brasil. \\ marilene@ensp.fiocruz.br
}

\begin{abstract}
This article presents some results from a study aimed at analyzing the limits and possibilities defined by inter-subjective and unconscious processes of solidarity, cooperation, and life care production in health services. A public hospital with an emergency department in the city of Rio de Janeiro, Brazil, was selected as a case study. The French school of psychosociology, oriented by the psychoanalytical clinical approach, the psychoanalytical theory on inter-subjective and group processes, and work psychodynamics provided the basis for the study's methodological strategies and analysis of the results. The study analyzed health professionals' psychological representations and unconscious processes related to emergency department users and their demands, and their consequences for the health care provided to this clientele. Some particularly important images such as "need" were used as a category that conceals the diversity of demand, in an unconscious process with multiple reductions: from denial of social suffering to denial of the patients' human condition.
\end{abstract}

Packaged Hospitals; Health Personal; Delivery of Health Care
Marilene de Castilho Sá 1

Teresa Cristina Carreteiro 2

Maria Inês Assumpção Fernandes 3

\section{Introdução}

Este artigo apresenta parte dos resultados de uma investigação cujo objetivo foi analisar, em um hospital de emergência, as conseqüências dos processos intersubjetivos e inconscientes presentes nos serviços de saúde para o exercício da solidariedade, para a cooperação e para a produção do cuidado 1 .

Os hospitais de emergência sofrem, mais do que outras unidades, os efeitos da falta de investimento no sistema público de saúde e de sua crise de governabilidade. Portas abertas 24 horas por dia, tornam-se espaços privilegiados de manifestação da exclusão social, da violência e da indiferença com relação ao outro, característicos da dinâmica social contemporânea.

Diante da complexidade desses processos, vimos, com outros autores $2,3,4,5,6,7,8,9$, reconhecendo a insuficiência da racionalidade sistêmico-estratégica das teorias de planejamento e gestão para fazer face à ineficiência e à baixa qualidade dos serviços de saúde que, paradoxalmente, produzem sofrimentos, seqüelas e mortes. Estes resultados nos levam, particularmente, a examinar a dimensão intersubjetiva e inconsciente das organizações de saúde 1,7,8,9,10,11 pela importância dos seus efeitos na qualidade do cuidado produzido.

Entendemos que os sujeitos se ligam ao seu trabalho e às organizações não apenas por vínculos materiais, mas, sobretudo, afetivos e imaginá- 
rios 12,13,14. A natureza e qualidade desses vínculos e das interações entre profissionais e usuários dos serviços definirão os limites e possibilidades de solidariedade, cooperação e cuidado.

A especificidade do trabalho em saúde apresenta também implicações sobre as possibilidades de solidariedade e cuidado ${ }^{1}$. Trata-se de um trabalho essencialmente intersubjetivo, uma intervenção de um sujeito sobre outro, em suas experiências de vida, prazer, dor, sofrimento e morte. Um dos desafios deste trabalho é, na perspectiva psicanalítica 15,16, o fato de que os homens não vêem seus semelhantes apenas como apoio ou fonte de conforto, mas igualmente como fonte de perigos, ameaça, o que impõe sérios limites à disposição para a solidariedade e cuidado com o outro. Do mesmo modo, lidar com a dor, com a morte, com o sofrimento e com os corpos dos outros pode despertar, como há muito o demonstrou Menzies 17, sentimentos contraditórios, fantasias e desejos difíceis de controlar - piedade, compaixão, amor, ódio e ressentimento, nojo, repulsa, por exemplo.

Assim, pela centralidade de sua dimensão relacional e intersubjetiva, o trabalho em saúde é altamente exigente de trabalho psíquico, entendido aqui como a produção de processos e formações inconscientes 18, como as fantasias, as ilusões, as alianças inconscientes, as identificações e as estratégias de defesa contra o sofrimento psíquico no trabalho 19 .

Essas exigências de trabalho psíquico podem ser intensificadas pelas condições materiais e pelo contexto organizacional e social em que o trabalho em saúde se realiza, com impactos na dinâmica prazer-sofrimento no trabalho e, igualmente, nas formas de organização do trabalho e em sua qualidade.

Para o presente artigo, privilegiamos apresentar, do conjunto dos resultados da pesquisa, aqueles derivados da análise das representações psíquicas e processos inconscientes relativos à população e suas demandas, produzidos pelos trabalhadores de saúde do hospital, discutindo suas conseqüências sobre a produção do cuidado, entendido como produção de "processos de falas e escutas, relações (...) com o mundo subjetivo do usuário (...) [com o modo como ele constrói suas necessidades de saúde], relações de acolhimento e vínculo, posicionamento ético, articulação de saberes para compor projetos terapêuticos..." 5 (p. 103).

\section{Metodologia}

A Psicossociologia francesa, de inspiração clínica psicanalítica $12,13,14,20,21$, a teoria psicanalíti- ca sobre os processos intersubjetivos e grupais 15,18,22,23,24,25 e a Psicodinâmica do Trabalho 19 são os referenciais que orientaram a investigação. Da Psicossociologia destacamos a compreensão das relações que os sujeitos estabelecem com as organizações, apoiadas, sobretudo, em vínculos afetivos e imaginários 12,13,14. A teoria psicanalítica apóia a leitura da dimensão relacional e intersubjetiva do trabalho em saúde, altamente exigente de trabalho psíquico 15,16,17,18 e suas implicações sobre a qualidade do cuidado, que também sofre impacto das estratégias de defesa dos trabalhadores contra o sofrimento psíquico no trabalho, objeto de análise da Psicodinâmica do Trabalho 19 .

Elegemos como estudo de caso um hospital geral, público, no Município do Rio de Janeiro, Brasil, com 198 leitos, serviço de emergência 24 horas e um serviço de pronto-atendimento. O estudo concentrou-se na Porta de Entrada, incluindo a Recepção, a Triagem, o Setor de Emergência e o Serviço de Pronto-Atendimento.

A pesquisa foi realizada entre maio de 2002 e março de 2004, compreendendo: participação em reuniões da equipe de direção e reuniões individuais com alguns de seus membros (totalizando 23 reuniões); 13 entrevistas individuais e 4 em grupo com profissionais do setor de Emergência/Porta de Entrada; 18 entrevistas individuais com profissionais das enfermarias; 18 observações participantes na recepção do Serviço de Pronto Atendimento e da Emergência, no setor de Registro, na espera (filas e sala de espera), nas dependências do Serviço de Pronto Atendimento e do Setor de Emergência com duração média de 4 horas cada; e observação dos atendimentos prestados a 9 pacientes, acompanhando-os desde sua chegada no Serviço de Pronto Atendimento ou na Emergência até sua saída.

Três eixos de análise orientaram o desenvolvimento da pesquisa: (1) o exame do imaginário 13,26 (representações inconscientes, fantasias, desejos, ilusões, expressos em metáforas, imagens e significações compartilhados pelos sujeitos na organização) sobre o hospital, sobre seu trabalho e sobre a população ali atendida; (2) o exame das formações intermediárias e espaços comuns da realidade psíquica 18 - expressos através de pactos e contratos inconscientes - produzidos e gerenciados pela organização a partir das contribuições e investimentos que ela exige dos trabalhadores; e (3) a análise da relação entre trabalho, prazer e sofrimento psíquico e das estratégias de defesa dos trabalhadores contra o sofrimento 19. Para o presente artigo privilegiamos as análises realizadas a partir dos dois primeiros eixos.

Registros escritos das observações participantes, do diário de campo e transcrições das 
gravações das entrevistas realizadas constituíram o material empírico sobre o qual se organizou a análise. Este material foi classificado e ordenado segundo as categorias de análise contidas nos três eixos acima assinalados. Na perspectiva metodológica adotada, o processo de classificação e ordenação do material empírico é parte indissociável do processo de interpretação.

A interpretação dos resultados seguiu os procedimentos da abordagem psicossociológica: análise clínica dos discursos, centrada na problemática do sofrimento e da produção de sentido pelos sujeitos em interação, apoiada na atenção flutuante do pesquisador e na consideração dos aspectos contratransferenciais emergentes de sua relação com as situações observadas e com os sujeitos da pesquisa. Esta perspectiva compreende várias instâncias de análise dos processos organizacionais 13 , reconhecendo a irredutibilidade entre elas, mas igualmente sua interconexão: o nível individual, o grupal, o organizacional, com sua realidade material, histórico-social e psíquica.

A pesquisa foi realizada em conformidade com os princípios éticos e condições para pesquisas envolvendo seres humanos estabelecidos na Declaração de Helsinki (1989) e na Resolução no. 196/96 do Conselho Nacional de Saúde.

\section{A enormidade da demanda e a demanda por sentido}

Trabalhar na Porta de Entrada de um hospital público de emergência é ser interpelado por uma demanda a qual dificilmente se poderá responder. Esta, além do excessivo volume, não se esgota no que, stricto sensu, se considera um problema de saúde e em muito ultrapassa o que os serviços de saúde estão geralmente organizados para reconhecer e intervir.

A frase, muito repetida pelos profissionais, “Tudo bate na Porta de Entrada", além de remeter aos problemas produzidos na própria dinâmica interna do hospital, indica, principalmente, a enormidade e a diversidade da demanda que ali chega.

O contexto de intensificação dos processos de exclusão social e de violência urbana, de precarização das relações de trabalho e fragilidade dos vínculos sociais leva aos serviços de saúde muitos sujeitos que, quando confrontados à doença, sentem que o mundo "desaba” 27. Trata-se, assim, de uma demanda não apenas material, mas simbólica, por amparo. Uma das imagens que talvez melhor traduzam este processo foi fornecida por um dos médicos que, tentando justificar o "atendimento rápido" que realizava, queixou-se da população, que “...chega ao hospital como se aqui fosse a Porta da Esperança!”.

A mesma imagem foi utilizada por um senhor que, após mais de duas horas na fila, quando estava quase chegando à porta da sala de triagem, disse: "estou quase chegando na Porta da Esperança”.

Luz 28, discutindo o crescimento "exponencial” da busca por atenção à saúde, entende que a demanda pela saúde é uma demanda por símbolos. Os cuidados, práticas e saberes em saúde estariam hoje, para a autora, no lugar das relações de empatia entre os sujeitos.

Claro está que o cenário "dantesco" dos corredores superlotados dos hospitais de emergência no Rio de Janeiro, invadidos pela violência urbana ${ }^{29}$, não é o espaço para o exercício da função social/cultural que, segundo a autora, teriam as práticas terapêuticas (incluindo as chamadas "alternativas") restritas, em geral, aos consultórios e clínicas privadas. Isto não significa dizer, no entanto, que a "demanda por símbolos" - na verdade, entendemos, uma demanda por sentido - não esteja presente entre a população que busca os serviços de públicos de emergência.

Exemplares dessa demanda por sentido são as referências dos profissionais aos pacientes que estão sempre presentes no Serviço de Pronto-Atendimento (SPA) como aqueles que "vivem de SPA", muitos dos quais "conhecidos pelo no$m e$ ". Embora a grande maioria dessas situações de retorno expresse a falência do sistema de saúde em sua capacidade de tratar, controlar e prevenir as doenças, não se pode desconhecer o que representam também de demandas de outra ordem. "Têm certos pacientes que a gente já até conhece (...) idosos, que não têm ninguém, que estão excluídos da sociedade (...) vêm aqui porque é o lazer deles: vir conversar com a gente!" (enfermeira da triagem).

Do mesmo modo, uma outra enfermeira destaca o tempo que passa, muitas vezes, com um único paciente, atendendo a uma população que, para esta enfermeira, é "doente de orientação".

Referências a este sofrimento tão amplo e difuso também se observam em falas que destacam, desta demanda, seu componente "afetivo" e de busca de reconhecimento: “...uma carência até afetiva..." (assistente social); "acho que a população busca o [hospital] até pela atenção que recebe aqui (...) um pouco de atendimento com dignidade..." (recepcionista). 


\section{As demandas por medicamentos e atestados médicos: entre a miséria material e simbólica}

Dois tipos de demanda muito freqüentes ao hospital parecem condensar a multiplicidade de determinações do sofrimento que bate à porta dos serviços de saúde: a busca por medicamentos e por atestados médicos. Tais demandas tensionam cotidianamente a relação entre os profissionais e a população e podem ser interpretadas, a partir de Carreteiro 21 - independentemente dos processos orgânicos que as justifiquem - como demandas dos indivíduos pelo reconhecimento de sua identidade de cidadãos, mesmo que tal identidade seja "negativa", dada através da condição de doente ou inválido, ou que tal reconhecimento institucional reforce o aspecto negativo implicitamente localizado em sua posição social de "desfavorecidos".

Para a autora 30 , o "sofrimento social" pode ser decorrente do não reconhecimento social ou de uma representação de "inutilidade" social, ou ainda do medo de perder a condição de trabalhador e passar à esfera da inutilidade. "A sensação de inutilidade (...) é sempre geradora de sofrimento psíquico, o qual, por ter uma raiz social, deve ser considerado sofrimento social" 30 (p. 93).

Este tipo de sofrimento não encontra, todavia, reconhecimento institucional na esfera da proteção social. "Esta só confere lugar à subjetividade dentro de duas perspectivas: corpo são, corpo doente, o que acarreta dizer que o sofrimento social, para obter reconhecimento institucional, o faz através da doença" 30 (p. 93).

A baixa capacidade de acolhimento e resolução da rede básica de serviços do Rio de Janeiro foi evidenciada como um dos agravantes da crise sem precedentes vivida pelos hospitais de emergência do município, entre 2004 e 20051. Neste contexto, a irregularidade do fornecimento de medicamentos é responsável pela maior parte da demanda por medicamentos que chega ao Serviço de Pronto Atendimento/ Emergência. Esta é uma questão geradora de conflitos na priorização dos pacientes, estando em jogo não só os critérios objetivos de urgência mas, como o demonstram Oliveira 31 e Rosa 32 , a possibilidade de reconhecimento do sofrimento da população pelas imensas dificuldades de acesso aos serviços públicos de saúde. Receber o medicamento, além da possibilidade de alívio dos sintomas e/ou tratamento das doenças, representa o reconhecimento do direito de acesso aos serviços e talvez também de acesso a uma identidade, dada pelo diagnóstico da doença a qual a medicação se destina. Receber a medicação insere o sujeito numa "rede de sentido" 21 , representando uma possibilidade de saída de uma situação de sofrimento social difuso, com o reconhecimento e a nomeação do mal-estar e sua transformação em um sintoma ou patologia definida, mesmo que isso implique uma negação da origem social do sofrimento e sua redução à uma dimensão individual.

Um enfermeiro ilustra bem esta demanda simbólica por medicamentos, muitas vezes "um presente" ou um "alívio" para sofrimentos de outra ordem: "existe aquele paciente que adora vir na emergência! (...) Adora ser medicado na emergência! (...) porque a pessoa vem com um certo (...) eu não vou dizer um prazer, porque ninguém tem prazer em ficar doente! Mas a gente observa que quando ele sai da emergência com o papel na mão, é como se ele saísse com um presente! Quando ele sai com uma receita, balançando, ou uma furada no braço, você tem que observar a expressão de alivio! Mesmo que essa injeção seja uma dipirona, que dói muito".

Da mesma forma, a demanda por atestados médicos no hospital estudado se constitui em um importante ponto de tensão na relação entre os profissionais e a população, com conflitos em torno de demandas por reconhecimento não só do direito, apoiado na condição fisiopatológica, mas do sofrimento. O sentimento de estar sendo "lesado" ou "enganado" parece prevalecer. É como se os médicos, diante de um paciente que julgam não estar doente, mas que insiste em receber o atestado, se sentissem enganados - "Tem gente que arma”, observou uma médica. Por sua vez, os pacientes, ao verem seus pedidos de atestado negados, se sentem lesados, naquilo que consideram ser seu direito, e também pelo não reconhecimento de seu sofrimento ou de sua condição de doente.

Entre os médicos, os ortopedistas são os que mais sistematicamente se negam a fornecer atestados, mesmo quando os casos, na visão dos demais profissionais, assim o exigiriam. "Eles simplesmente dizem: 'não dou e pronto' (...) Todo mundo sabe disso. Há até piadas: são muito rudes porque lidam com osso (...) só vêem o osso, não se interessam pela relação com o paciente".

A metáfora de "só ver o osso" parece representar bem a impossibilidade - da própria lógica dominante de organização da assistência à saúde - de reconhecimento do que Carreteiro 21,30 denominou "sofrimento social", a menos que este sofra uma redução (aliás, uma expressão própria de procedimentos ortopédicos de intervenção em fraturas) para a dimensão concreta, material da doença, localizada precisamente no corpo. 


\section{A "carência" como categoria encobridora da diversidade da demanda}

Mas a miséria que todos os dias bate à porta do hospital não é só, evidentemente, a miséria simbólica. É também a miséria material que atinge maciçamente vastos segmentos da população.

Um enfermeiro queixa-se da população de rua que "invade" o espaço da espera da emergência e do Serviço de Pronto Atendimento e “...dormem nos bancos, urinam pelo chão...”.

Segundo um médico, “...as pessoas estão cada vez mais revoltadas e ignorantes (...) Trata-se de uma clientela de baixo nível cultural, social e completamente maltratada - socialmente e aqui no hospital - são jogados numa maca sem coberta (...) comem sem talher, como bichos, tendo que cortar a carne com os dentes...". Afirma ainda que a situação deles é tão adversa que aceitam aquela comida e buscam abrigo no hospital. "Vão ficando por aqui...".

Uma enfermeira conta que alguns médicos mandam internar desnecessariamente pacientes na emergência para que lhes seja dado banho e só então os examinam.

Observamos duas enfermeiras atendendo na pequena e abafada sala da triagem, por mais de uma hora, após um paciente ter ali vomitado, sem que ninguém aparecesse para limpar a sala.

Assim, trabalhar na Porta de Entrada de um hospital público de emergência é também estar cara a cara com uma demanda que assume a forma dos maus tratos, da feiúra, da brutalidade, da sujeira e do mau cheiro, situações, para muitos profissionais, insuportáveis e até mesmo impossíveis de serem representadas, significadas.

“Tudo bate na Porta do Hospital". Esta frase, no entanto, se indica a enormidade e diversidade da demanda, não a revela, não permite identificar sua heterogeneidade, encoberta sob o "tudo", um enorme amálgama de demandas de diversas ordens às quais os trabalhadores da Porta de Entrada se sentem implicados, mas incapazes de responder ou suportar

Esse processo de encobrimento da heterogeneidade da demanda começou a se tornar acessível quando consideramos a elevada freqüência com que os profissionais, ao serem solicitados a falar da população, utilizavam a categoria " $c a$ rência" para defini-la. As referências à população como "carente", "muito carente", “carente de tudo" eram quase unânimes e praticamente inexistentes as referências espontâneas a outras características da população.

Aqui é interessante recuperarmos os trabalhos de Paugam 33, que contrapõe a noção de "processo de desqualificação social" ao conceito de "pobreza". Este não permitiria caracterizar a heterogeneidade da população, ocultando a origem diferenciada das dificuldades dos indivíduos e seus efeitos a longo prazo.

Esta discussão nos ajuda a pensar, por analogia, a função de "encobrimento" que a categoria "carência" estaria exercendo no hospital estudado, agrupando, num conjunto, "homogeneizando", sujeitos e grupos sociais cujas trajetórias, ainda que possam apresentar interseções, se diferenciam nas formas de inserção social, nas relações com os serviços, nas maneiras como se produzem e se manifestam seus problemas e também nas formas de seu sofrimento.

Claro que a utilização da expressão "carente" / "carente de tudo", emerge naturalmente da constatação da penúria cotidiana, real, vivida pela população. Não se trata de negar isto. Mas é como se a idéia de "carência" mantivesse os profissionais, paradoxalmente, "colados" a este real, sem capacidade de distanciamento, de elaboração, enfim, sem possibilidade de uma reflexão mais produtiva - porque apoiada que poderia ser em múltiplas representações - sobre a realidade em que atuam e sobre o outro com quem interagem.

A hipótese de que a utilização da idéia de "carência" estaria a serviço de um processo psicossociológico de encobrimento da heterogeneidade da população e de suas demandas se apóia também indiretamente no trabalho de Fernandes 25 a respeito da negatividade na construção dos laços sociais, tendo como foco, na história da sociedade brasileira, a ideologia da mestiçagem, que permitiria o sentimento de união, supostamente apagando as diferenças e encobrindo, de fato, práticas discriminatórias. A análise de Fernandes é tomada aqui como uma analogia para exemplificar os processos de alianças inconscientes produzidos no hospital estudado.

A autora desenvolve sua análise a partir do conceito de "alianças inconscientes" de René Kaës, "uma formação psíquica intersubjetiva construída pelos sujeitos de um vínculo para reforçar, em cada um deles, certos processos, certas funções, ou certas estruturas das quais eles tiram um benefício tal que a ligação que os mantêm juntos toma para sua vida psíquica um valor decisivo" 25 (p. 129).

Apoiada em Kaës, Fernandes 25 observa que o conceito de diferença aparece relacionado, na obra de Freud, aos seguintes significados: (1) ao conceito de estrangeiro, cuja imagem é associada inicialmente a desprazer e hostilidade. Neste sentido, forma a categoria do não-eu (non-moi); (2) à experiência persecutória e depressiva da perda de uma certa unidade (mãe/filho), reorganizando as relações dentro/fora e definindo a categoria do não vínculo (non-lien) e da separação; (3) à alteridade, referindo-se, em última análise, 
à confrontação com a diferença de sexos e entre as gerações. Constitui a categoria do não-o mesmo (non-le même); e (4) à experiência da saída do grupo familiar e à necessidade de rearranjar, através do acesso à escola, fundamentalmente, a relação entre a Lei, as normas experimentadas na família e as que estão fora dela. Constituiria aqui a categoria do não-nós (non-nous). São categorias que apresentam a diferença sempre marcada pelo signo do Negativo.

Pensamos que a utilização, pelos profissionais entrevistados, da categoria "carência" para representar o outro que bate à porta do hospital e suas demandas estaria cumprindo um papel de encobrimento ou apagamento das diferenças, mas com funções psíquicas bastante específicas e diversas das que Fernandes 25 sugere, pois não se apresentaria com o "sinal positivo" da harmonia de contrários, da ausência de conflitos ou da igualdade no conjunto social mais amplo representado pelos trabalhadores e a população atendida.

\section{Do sofrimento social aos corpos sem subjetividade}

No hospital estudado, a representação da população como "carente" parece ser o resultado de um processo de alianças inconscientes, entre os trabalhadores, que assumiriam a forma de um pacto denegativo, cumprindo dois tipos de funções:

1. Apagando as diferenças, na população, de inserção social e nas formas de viver, adoecer e morrer, a categoria "carência", estaria possibilitando aos trabalhadores do hospital não ver/não representar o que não podem ou ao que não se sentem capazes de responder (neste caso, uma defesa contra o sofrimento que a consciência da diversidade da demanda, $v i s$ - $a ̀-$ vis os limites organizacionais impostos ao seu trabalho, produziria). Ou ainda, o que parece mais provável, a "carência", apagando as diferenças internas da população, possibilitaria aos trabalhadores não ver o que não querem ver: as semelhanças entre eles e a população, que mais facilmente se evidenciariam caso a heterogeneidade da população fosse nomeada. Neste caso, a categoria "carência" estaria afirmando as fronteiras que distinguiriam os profissionais da população, "estranha" / "estrangeira", cuja visão causa aos primeiros desprazer e hostilidade. A "carência" conformaria aqui a categoria do nãoeu (non-moi) e também a categoria do não-nós (non-nous), representando aqueles que não nos são "familiares" - ou com quem não queremos parecer familiares.
Algumas poucas falas denunciam tal encobrimento quando revelam aquilo que é encoberto, isto é, estas semelhanças ou identidades: "Aqui todo mundo é carente, até o funcionário!” (médica cirurgiã da emergência). Ou a fala de uma outra médica da emergência, após avisar que na enfermaria de curta permanência havia dois pacientes com tuberculose "multidroga resistente", sem isolamento: "Nós aqui somos todos pobres coitados: os pacientes, os familiares, os médicos (...) todos que trabalham aqui! Isto é o fim!".

O "risco do contágio" é real, sem dúvida, mas também imaginário, com conseqüências talvez mais perigosas sobre os resultados e a qualidade do trabalho. A precariedade e a carência do hospital, de seus trabalhadores e da população atendida se fundem e se confundem.

Do mesmo modo que são poucas as falas a denunciar as identidades, são poucas a expressar a hostilidade, a raiva, pela brutalidade de uma carência com a qual dificilmente os funcionários podem se identificar, mas na qual irremediavelmente estão implicados, porque são demandados a responder. A representação da população como "carente" parece, assim, não apenas apagar as semelhanças entre funcionários e população, mas também diluir/encobrir alguns afetos - como o ódio pela sujeira, pela "ignorância”, pela brutalidade do outro - que, entretanto, mesmo pontualmente, se manifestam.

Uma enfermeira da emergência, num dia de superlotação, chamou o vigilante e pediu que fizesse "uma limpa" no local, retirando os familiares/acompanhantes. Mais tarde, comentou com o mesmo vigilante a respeito da filha de um paciente idoso: "É uma escória!".

Em um dos plantões observados, quatro bebês graves necessitavam transferência para outros hospitais e não se conseguiam vagas. $\mathrm{Na}$ véspera, uma pediatra havia sido agredida fisicamente pelos responsáveis por uma criança. O sentimento de insegurança entre os profissionais aumentava na medida em que a empresa de vigilância havia suspendido os serviços devido à não renovação do contrato. No restaurante do hospital, o Diretor perguntou a uma das pediatras pelos bebês que precisavam de transferência. A médica, irritada, responsabilizou uma das famílias por ter demorado a trazer a criança. Disse, continuando a se servir de feijão, que a criança não agüentaria até as quatro horas da tarde, que iria morrer e, referindo-se ao episódio da médica agredida, observou: "Eu não sou igual a ela não! Porque isso não é gente: é sub-raça!".

Nos aproximamos, assim, do segundo tipo de função psíquica que a representação da população como "carente" estaria cumprindo, possivel- 
mente relacionada a processos psíquicos mais violentos ou mortíferos.

2. Encobrindo ou apagando aquilo que no outro é traço do humano, a "carência" permitiria ao conjunto intersubjetivo formado pelos trabalhadores do hospital marcar uma separação, um afastamento e uma diferença radical com relação a este outro, cuja proximidade é ameaçadora, não apenas pela miséria - material e simbólica - com a qual não podem se identificar, como pela violência presente nesta relação. A "carência", constituindo as categorias do não-vínculo (non-lien) e do não-o mesmo (non-le même), permitiria não só demarcar rigidamente as fronteiras trabalhadores-população - reduzindo esta última ao não humano - como mascarar (negar) a violência simbólica (objeto último do pacto denegativo) desta redução produzida pelos serviços (a rigor, pela sociedade) sobre a população ali atendida.

O depoimento de um cirurgião pode ser considerado paradigmático desse tipo de processo psicossociológico. Contou o caso de uma paciente atendida na emergência, que havia sido atingida por uma bala perdida, enquanto amamentava seu filho. A bala entrou pelas costas e atravessou sua vagina. Observou, indignado, que "a única preocupação da moça era se poderia ter mais filhos, se sua vagina voltaria ao normal, porque seu marido queria mais filhos!". Para ele, isto era um "absurdo", uma demonstração de "ignorância", pois, na situação de miséria em que ela vivia, não deveria pensar em ter mais filhos.

A categoria "carência”, paradoxalmente totalizante e redutora, retira assim do outro sua dimensão desejante, sua condição de humanidade.

A população parece ser submetida, assim, a um processo de múltiplas reduções: do sofrimento social à doença individual 21,30; do humano ao humanitário (Calligaris, 1994, apud Fernandes 25) ou do político ao humanitário (Lasch, 1983, apud Fernandes 25) e ainda, acreditamos, do humano ao "não-humano", isto é, ao outro reduzido a um corpo sem desejo, só com "necessidades" - biologicamente definidas - enfim, um corpo sem subjetividade.

A violência de tal redução, todavia, parece ser denegada, através da própria utilização da categoria "carência", que em geral se faz acompanhar de expressões de pena, piedade, comiseração.

Aqui é interessante recuperar a distinção entre compaixão e piedade trazida por Sawaia 34 da obra de Hanna Arendt. Enquanto a compaixão é um sofrimento que nos mobiliza para a ação social/política, a piedade seria a "paixão pela compaixão", um sentimento que encontra em si mesmo seu próprio prazer.
A piedade distingue-se do que Sawaia denomina "sofrimento ético-político", o sofrimento pela consciência de como a lógica excludente opera. O sofrimento ético-político estaria do lado da compaixão. A autora recupera uma descrição de Simone Weil sobre sua experiência como operária para representar este tipo de sentimento: "Estando na fábrica (...) a infelicidade dos outros entra na minha carne e na minha alma (...) Eu recebi a marca da escravidão" (Weil, 1979, apud Sawaia 34 , p. 105).

Esta descrição põe em evidência, acreditamos, a centralidade dos processos identificatórios 15,16 na mobilização da compaixão e se revela importante para pensarmos os impasses da solidariedade e do cuidado com a vida nos serviços de saúde. Na piedade não haveria identificação, nem, conseqüentemente, mobilização para a ação. Pensamos que no trabalho em saúde, a piedade alimenta a apatia, o conformismo e a prestação da assistência como um favor ou caridade, sendo, talvez, o que de melhor possa emergir da relação com o outro reduzido à categoria do "não-o mesmo", à dessemelhança radical.

\section{Considerações finais}

Iniciamos este artigo afirmando que trabalhar num hospital público de emergência é ser interpelado por uma demanda que em muito ultrapassa o que os serviços estão organizados para reconhecer e intervir.

Nossa investigação constata que este "estar organizado" não se restringe às condições materiais, tecnológicas e de pessoal. Envolve igualmente a forma de organização e gestão dos processos de trabalho, mas também aí não se esgota. É preciso também refletir sobre como está "organizado" esse universo simbólico e imaginário compartilhado pelos sujeitos no hospital. Que representações psíquicas, que imagens (e afetos a elas vinculados) são produzidas sobre o hospital, sobre a população e suas demandas, sobre o trabalho ali realizado, sobre os trabalhadores? Que funções psíquicas estariam cumprindo? Que processos intersubjetivos são produzidos ou são possíveis neste espaço imaginário e simbólico conformado pelo hospital?

Só assim podemos começar a compreender e a buscar formas mais efetivas de encurtar a distância que nos separa, por exemplo, da "imagem-objetivo” desenhada por Cecílio 3 (p. 119), quando considera que "um episódio de internação hospitalar pode ser uma situação privilegiada para se estabelecer vínculos, mesmo que temporários e se trabalhar a construção da au- 
tonomia do 'paciente"'. Ou ainda que "o atendimento em um serviço de emergência pode ser um momento crucial para a escuta da necessidade de consumo de certas tecnologias para melhorar e prolongar a vida". Ou então que "uma consulta médica, por mais especializada que seja, não pode deixar de fazer uma certa escuta de outras necessidades do paciente que vão além da demanda 'referenciada' que o traz ao consultório". Como o próprio autor conclui, "simples como idéia. Muito difícil de implementar na prática” 3 (p. 119).

O que verificamos no material aqui apresentado é que os processos psicossociológicos que condicionam o imaginário sobre a população e a forma como suas demandas são escutadas marcam uma distância quase que incomensurável entre a realidade dos serviços de saúde e a imagem de futuro traçada acima.

\section{Resumo}

Este artigo apresenta parte dos resultados de uma in vestigação voltada para a análise dos limites e possibilidades que os processos intersubjetivos e inconscientes presentes nos serviços de saúde estabelecem para o exercício da solidariedade, para a cooperação e para a produção do cuidado com a vida. Elegeu-se como estudo de caso um hospital público de emergência, situado no Município do Rio de Janeiro, Brasil. A Psicossociologia francesa, de inspiração clínica psicanalítica, a teoria psicanalítica sobre os processos intersubjetivos e grupais e a Psicodinâmica do Trabalho são os referenciais centrais que orientaram o desenho da investigação e a análise do material empírico. As representações psíquicas e os processos inconscientes relativos à população e suas demandas, produzidos pelos trabalhadores de saúde do hospital estudado, foram analisados, discutindo-se suas conseqüências sobre a produção do cuidado. Algumas imagens se destacaram, como a "carência", utilizada como uma categoria encobridora da diversidade da demanda, num processo inconsciente de múltiplas reduções: da negação do sofrimento social à negação da condição de humanidade dos pacientes.

Hospitais de Emergência; Pessoal de Saúde; Assistência à Saúde
Embora a face "mortífera" dos processos organizacionais e psíquicos seja apenas uma de suas faces 12,13, no caso em questão (e, sustentamos a hipótese, na grande maioria dos serviços de saúde) ela é dominante, manifestando-se no espaço cotidiano da realização do trabalho. Contudo, devemos considerar que esses espaços, justamente por se caracterizarem como processos de "trabalho vivo em ato" 5 , sempre guardarão possibilidades de desencadeamento de processos criativos e de ligação com o outro, bases para a responsabilidade e o cuidado. Para isso, o acesso a este universo simbólico e imaginário que atravessa os serviços de saúde, e ao sentido que o mesmo confere à vida organizacional, deve ser buscado, tanto pelos gestores quanto pelos trabalhadores, como condição para a melhoria da capacidade de escuta e resposta à população e suas demandas.

\section{Colaboradores}

M. C. Sá executou a pesquisa, a análise dos resultados e a redação do artigo. T. C. Carreteiro e M. I. A. Fernandes contribuíram no desenvolvimento teórico-metodológico da pesquisa, na concepção do artigo e na discussão de seus resultados. 


\section{Referências}

1. Sá MC. Em busca de uma Porta de Saída: os destinos da solidariedade, da cooperação e do cuidado com a vida na porta de entrada de um hospital de emergência [Tese de Doutorado]. São Paulo: Universidade de São Paulo; 2005.

2. Campos GWS. Um método para a análise e co-gestão de coletivos: a constituição do sujeito, a produção de valor de uso e a democracia em instituições - o método da roda. São Paulo: Editora Hucitec; 2000.

3. Cecílio LCO. As necessidades de saúde como conceito estruturante na luta pela integralidade e eqüidade na atenção em saúde. In: Pinheiro $R$, Mattos RA, organizadores. Os sentidos da integralidade na atenção e no cuidado à saúde. Rio de Janeiro: Instituto de Medicina Social, Universidade do Estado do Rio de Janeiro/ABRASCO; 2001. p. 113-26.

4. Cecílio LCO. Propostas alternativas de gestão hospitalar e o protagonismo dos trabalhadores: por que as coisas nem sempre acontecem como os dirigentes desejam? Saúde Soc 2004; 13:39-55.

5. Merhy EE. Saúde: a cartografia do trabalho vivo. São Paulo: Editora Hucitec; 2002.

6. Campos RO. O planejamento no labirinto: uma viagem hermenêutica. São Paulo: Editora Hucitec; 2003.

7. Sá MC. O mal-estar nas organizações de saúde: planejamento e gestão como problemas ou soluções? Ciênc Saúde Coletiva 1999; 4:255-8.

8. Sá MC. Subjetividade e projetos coletivos: malestar e governabilidade nas organizações de saúde. Ciênc Saúde Coletiva 2001; 6:151-4.

9. Azevedo CS, Braga Neto FC, Sá MC. O indivíduo e a mudança nas organizações de saúde: contribuições da psicossociologia. Cad Saúde Pública 2002; 18:235-47.

10. Sá MC, Azevedo CS. Trabalho gerencial e processos intersubjetivos: uma experiência com diretores de hospitais públicos. Rev Adm Pública 2002; 36: 507-27.

11. Azevedo CS. Sob o domínio da urgência: o trabalho de diretores de hospitais públicos no Rio de Janeiro [Tese de Doutorado]. São Paulo: Universidade de São Paulo; 2005.

12. Enriquez E. O trabalho da morte nas instituições. In: Kaës R, organizador. A instituição e as instituições: estudos psicanalíticos. São Paulo: Editora Casa do Psicólogo; 1989. p. 73-101.

13. Enriquez E. A organização em análise. Petrópolis: Editora Vozes; 1997

14. Lèvy A. Ciências clínicas e organizações sociais. Belo Horizonte: Autêntica Editora/FUMEC; 2001.

15. Freud S. Psicologia de grupo e análise do ego. Rio de Janeiro: Editora Imago; 1976. (Edição Standard Brasileira das Obras Completas de Sigmund Freud, XVIII).

16. Freud S. Inibições, sintomas e ansiedade. Rio de Janeiro: Editora Imago; 1976. (Edição Standard Brasileira das Obras Completas de Sigmund Freud, XX).

17. Menzies I. The functioning of organizations as social systems of defense against anxiety. London: Tavistok Institute of Human Relations; 1970.
18. Kaës R. O grupo e o sujeito do grupo: elementos para uma teoria psicanalítica do grupo. São Paulo: Editora Casa do Psicólogo; 1989.

19. Dejours C. Psicodinâmica do trabalho: contribuições da escola Dejouriana à análise da relação prazer, sofrimento e trabalho. São Paulo: Editora Atlas; 1994.

20. Gaulejac V. Psicossociologia e sociologia clínica. In: Araújo JNG, Carreteiro TC, organizadores. Cenários sociais e abordagem clínica. São Paulo: Editora Escuta/Belo Horizonte: Fumec; 2001. p. 35-47.

21. Carreteiro TC. Exclusion sociale et construction de l'identité. Paris: Édition L'Harmattan; 1993.

22. Freud S. O mal-estar na civilização. Rio de Janeiro: Editora Imago; 1976. (Edição Standard Brasileira das Obras Completas de Sigmund Freud, XXI).

23. Costa JF. A ética democrática e seus inimigos. In: Roitman A, organizador. O desafio ético. Rio de Janeiro: Editora Garamond; 2000. p. 77-89.

24. Birman J. Insuficientes, um esforço a mais para sermos irmãos! In: Kehl MR, organizadora. Função fraterna. Rio de Janeiro: Editora Relume Dumará; 2000. p. 171-208.

25. Fernandes MIA. Mestiçagem e ideologia: algumas reflexões sobre a negatividade na construção dos laços sociais [Tese de Livre-Docência]. São Paulo: Universidade de São Paulo; 2003.

26. Giust-Desprairies F. Representation et imaginaire. In: Barus-Michel J, Enriquez E, Lèvy A, organizadores. Vocabulaire de psychosociologie: références et positions. Paris: Éditions Érès; 2002. p. 231-50.

27. Machado FRS, Pinheiro R, Guizardi F. As novas formas de cuidado integral nos espaços públicos de saúde. In: Pinheiro R, Mattos RA, organizadores. Cuidado: as fronteiras da integralidade. São Paulo: Editora Hucitec/Rio de Janeiro: ABRASCO; 2004. p. 57-74.

28. Luz MT. Fragilidade social e busca de cuidado na sociedade civil hoje. In: Pinheiro R, Mattos RA, organizadores. Cuidado: as fronteiras da Integralidade. São Paulo: Editora Hucitec/Rio de Janeiro: ABRASCO; 2004. p. 9-20.

29. Deslandes S. Frágeis deuses: profissionais da emergência entre os danos da violência e a recriação da vida. Rio de Janeiro: Editora Fiocruz; 2002.

30. Carreteiro TC. A doença como projeto: uma contribuição à análise das formas de afiliações e desafiliações sociais. In: Sawaia B, organizadora. As artimanhas da exclusão social: análise psicossocial e ética da desigualdade social. 2a Ed. Petrópolis: Editora Vozes; 2001. p. 85-95.

31. Oliveira LH. Cidadãos peregrinos: os "usuários" do SUS e os significados de sua demanda a prontosocorros e hospitais no contexto de um processo de reorientação do modelo assistencial. Uma análise a partir dos usuários do SUS no Município de Juiz de Fora [Tese de Doutorado]. Rio de Janeiro: Universidade do Estado do Rio de Janeiro; 2004.

32. Rosa NG. Dilemas éticos no mundo do cuidar de um serviço de emergência [Dissertação de Mestrado]. Porto Alegre: Universidade Federal do Rio Grande do Sul; 2001. 
33. Paugam S. O enfraquecimento e a ruptura dos vínculos sociais: uma dimensão essencial do processo de desqualificação social. In: Sawaia B, organizadora. As artimanhas da exclusão social: análise psicossocial e ética da desigualdade social. 2a $\mathrm{Ed}$. Petrópolis: Editora Vozes; 2001. p. 67-86.
34. Sawaia B. O sofrimento ético-político como categoria de análise da dialética exclusão/inclusão. In: Sawaia B, organizadora. As artimanhas da exclusão social: análise psicossocial e ética da desigualdade social. 2a Ed. Petrópolis: Editora Vozes; 2001. p. 97 118.

Recebido em 24/Mai/2007

Versão final reapresentada em 05/Nov/2007

Aprovado em 08/Nov/2007 